\title{
Towards a coalition for research in library, archive and information science
}

\author{
Stephanie Kenna
}

\section{The research landscape}

...there is research going on, much of it ICT focussed, but it is piecemeal, of varying quality, with no co-ordination or coherence and poorly disseminated. There are no real think pieces being produced or encouraged. We have lost the locus / the space for research, within a co-ordinating framework. We have lost the continuity and the context, as well as the culture and the capacity.

(Elkin, 2007, 37)

On Friday 14 March 2008, a small group representing major stakeholders in library, archive and information science (LAIS) research met to address this situation and begin the process of establishing an LAIS research coalition for the UK. The aim of the coalition is to:

- Articulate a strategic and planned approach to research across the sectors;

- Identify appropriate research content;

- Encourage the development of research capacity;

- Ensure the inclusion of each sector.

\section{Looking back to the future}

This meeting was the culmination of a lengthy process of consultation and discussion across the sector. Its origins lie in a workshop entitled Looking Back to the Future, which was held at the British Library (BL) on 27 November 2006 in memory of Brian Perry, Director of the British Library's Research and Development Department (BLR\&DD), 1984-1995 ${ }^{1}$.

\footnotetext{
${ }^{1}$ The proceedings were published as a special edition of Library and Information Research, Volume 31 (97) 2007. Available at: http://www.lirg.org.uk/lir/ojs/index.php/lir/issue/view/2.
}

\section{Author}

Stephanie Kenna was a Research Analyst in the British Library Research and Development Department, subsequently the Research and Innovation Centre, from 1988 to 1999. She currently manages the British Library's regional programme.

Email: Stephanie.Kenna@bl.uk 
The members of the Steering Group ${ }^{2}$ who organised the 2006 workshop were keen that it would not only pay tribute to the achievements of Brian Perry and BLR\&DD, but that it would also stimulate lively debate and identify actions necessary for the creation of an effective framework to support library and information science (LIS) research in the UK.

Delegates rose to the challenge and highlighted a number of research themes and pointers for the future of LIS research. They also agreed that there was a need for a real or virtual structure to enable the organisation, co-ordination and implementation of strategic LIS research. Such a structure would also enable access to information about research by the LIS profession which, in turn, would engender more confidence that any research activity associated with their profession would be available in an understandable and useable way. In particular, there should be a focus on practitioner research and bringing research results into practice.

\section{Next steps}

In her summing up of the day, Professor Judith Elkin urged the British Library "to convene a Think Tank, a forum to get the key stakeholders around the table .... to re-establish a national LIS Research Agenda" (Elkin, 2007, 37), and the original Steering Group was "invited to plan the way ahead armed with the notes from the group discussion sessions and the papers from the speakers" (Macartney, 2007, 1).

The Steering Group subsequently reviewed the outputs from the day and proposed a way forward for discussion. A short statement was published on the conference website which:

- Emphasised that the coalition approach was the most strongly favoured of the options discussed of the workshop;

- Summarised aims, roles and functions of such a coalition as identified at the workshop;

- Identified key outputs;

- Listed potential stakeholders.

Updates from the perspectives of the working group, the British Library (BL) and the Museums Libraries and Archives Council (MLA) were well received at the Library and Information Research Group at the CILIP Umbrella event held at Hatfield in June $2007^{3}$. In addition the remit of the proposed framework was extended to encompass the archive community in order to reflect not only the original BLR\&DD remit but also the commonality of interests between the LIS and the archive professions.

\footnotetext{
${ }^{2}$ Mel Collier, University of Leuven; Biddy Fisher, Sheffield Hallam University; Stephanie Kenna, British Library; Nigel Macartney, University of Ulster (chair)

3 Speakers included: Nigel Macartney, chair of the working group; Stephanie Kenna, British Library; and Javier Staniziola, Museums Libraries and Archives Council.
} 


\section{Models for a coalition}

Delegates at the 2006 workshop suggested a number of possible models for a collaborative approach:

- A coalition of stakeholder organisations;

- Communities of researchers practitioners and funders co-ordinated by a stakeholder champion;

- The British Library acting as a broker, at least initially;

- A library development agency.

It was also felt that lessons could be learned from other initiatives such as the Joint Information Systems Committee (JISC) Strategic Content Alliance, local library co-operative organisations in the UK and the role played by the Danish National School of Librarianship in the co-ordination of national research activity.

The coalition approach was however the option most strongly favoured, not least because it would not be another new organisation.

In order to refine their thinking, the Steering Group commissioned Barbara Buckley Owen to investigate and develop a number of possible models. Her report (Buckley Owen, 2007, 2, 14) proposed three:

1. A membership organisation of "big players plus" with a core membership of key members but with associate members to draw in the wider profession.

2. A partnership of big players only with an onus on them to share results.

3. A central Champion to make things happen "plus" a membership.

A number of issues to take into account when developing a coalition were also identified:

- Key members;

- The need for champions within member organisations;

- A wide membership base;

- Sustainability over the long term;

- Centralisation versus decentralisation;

- Openness in sharing benefits;

- Funding;

- What success should look like.

The recommended model was the first: a membership-based organisation similar to the Digital Preservation Coalition (DPC). This seemed to offer the most appropriate mix of financial and practical commitment from key players, together with a wide spectrum of membership and mechanisms for consultation and dissemination. 


\section{Consultation with stakeholders}

The next critical stage in the establishment of a coalition, was achieving buy-in from stakeholders. Over the summer and autumn of 2007, therefore, members of the working group, usually in pairs, visited and consulted a range of key stakeholders, both large and small, including:

- Arts and Humanities Research Council (AHRC);

- British Association for Information and Library Education and Research (Bailer);

- British Library;

- Chartered Institute of Library and Information Professionals (CILIP);

- Cymal;

- Economic and Social Research Council (ESRC);

- Joint Information Systems Committee (JISC);

- Library and Information Services Council, Northern Ireland;

- Museums Libraries and Archives Council (MLA);

- National Council on Archives (NCA);

- National Health Service;

- National Library of Scotland;

- National Library of Wales;

- Research Information Network (RIN);

- Research Libraries UK (formerly CURL);

- Scottish Library and Information Council (SLIC);

- Society of Chief Librarians (SCL);

- Society of College, National and University Libraries (SCONUL);

- The National Archives (TNA);

- UK Office for Library Networking (UKOLN).

Discussion focused on how best each stakeholder might engage with the national research agenda, and on the desirability and practicality of establishing a coalition. The outcome was a unanimous endorsement of the recommendation from the 2006 workshop that an initiative should be undertaken to improve the infrastructure for library, archive and information research.

\section{The way forward}

Each stakeholder consulted was also invited to attend a second workshop, held at Universities UK in London on 30 November 2007. The objective was to review 
the work of the Steering Group and to consider outline proposals for a coalition including remit, draft constitution, road map and finance ${ }^{4}$.

The remit of the coalition which emerged from the 2006 workshop had been refined during consultation. The coalition would:

- Provide a locus of and for LAIS research;

- Define the LAIS research landscape;

- Develop a national research strategy, respecting differences across the UK;

- Co-ordinate and disseminate information about research;

- Exploit existing and leverage new funding;

- Promote practitioner research and research into practice;

- Broker research and funding partnerships;

- Promote best practice and the development of skills and competencies.

The coalition's constitution would be based on that of the DPC. The coalition would be established as a not-for-profit company limited by guarantee. It would be a membership organisation open to all LAIS stakeholders: subscriptions would be banded with either full (maximum subscription) or associate (reduced subscription) membership.

The business of the coalition would be managed by a Board of Directors consisting of representatives of full member organisations (initially likely to be the BL, CILIP, JISC, MLA and RIN) and two other representatives elected from among the associate membership. The Board would be supported by a Project Director based in one of the full member organisations. The post would be offered for an initial period of three years.

There would also be an Advisory Council which would act as a forum for circulation and sharing of information, support the activities of the coalition and advise the Board and Director on programme development. This would be open to non-members, both organisations and individuals, by invitation.

Priorities identified for the coalition by the 2006 workshop included:

- A Manifesto setting out aspirations, objectives which should demonstrate links between existing research, strategic and government agendas but also set out its own agenda;

- A roadmap to show how it will achieve its objectives;

- A 'Cream of Information Science' showcase of best practice and the facilitation of existing research information exchange;

- Consultation on and finalising the national research agenda.

\footnotetext{
${ }^{4}$ See Proposed Coalition for Research in Library, Archive and Information Science, Second workshop on library and information research, Friday 30 November 2007. Available at: http://www.bl.uk/services/information/pdf/workshop2007.pdf
} 
The roadmap proposed eleven action lines:

- Strategy

- Manifesto

- Services

- Dissemination

- Encouraging quality

- Advocacy

- Conference and showcase

- Organisation

- Personnel

- Finance and administration

- Review and evaluation.

A financial model was also provided to illustrate how the coalition and its work could be funded. This assumed that the major stakeholders would pay full subscriptions of $£ 9,500$ p.a. and that associate stakeholders would pay reduced subscriptions of $£ 1,000$ p.a. It was also suggested that some activity might be funded through research and other grants.

There was general agreement with the concept of a research coalition. Discussion highlighted the need for clarity of mission and purpose and the need both to define research in the LAIS context and to define research broadly in order to be inclusive.

There were formal statements of firm support for the establishment of a coalition along the lines proposed from a number of stakeholders including the major stakeholders and it was agreed that an Implementation Group consisting of representatives of the major stakeholders ${ }^{5}$, should be convened.

\section{Implementation group}

At the meeting on 14 March 2008 members of the original Steering Group formally handed over responsibility to the Implementation Group which identified priorities for action with the aim of formally establishing the coalition in the autumn of 2008.

Nigel Macartney, Chair of the Steering Group commented:

"The Steering Group had excellent support from all concerned in drafting its detailed proposals for the Research Coalition; it is now over to you, the professionals, to make this into reality. We all believe that the creation of a new driving force for LAIS research will help to strengthen and re-invigorate the whole sector. We wish the Implementation Group every success in their task."

\footnotetext{
${ }^{5}$ Biddy Fisher (CILIP), Michael Jubb (RIN), Stephanie Kenna (BL), Charles Oppenheim (JISC), Javier Stanziola (MLA).
} 
On behalf of the Implementation Group, Michael Jubb responded:

"The Implementation Group has been given an important and challenging task in seeking to ensure that we sustain the momentum established by the two workshops and the proposals developed by the Steering Group. We are convinced that the new Coalition has an important role to play in co-ordinating and driving forward a research agenda for the library, archives and information communities. Our job now is to make that a reality."

\section{References}

Buckley Owen, B. (2007) Models for a Coalition for Library and Information Science Research. London: British Library. URL:

http://www.bl.uk/services/information/pdf/threemodels.pdf [accessed 16.04.08].

Elkin, J. (2007) Overview of the Brian Perry commemorative workshop: looking back to the future; research agendas for library and information science. Library and Information Research, 31(97), 36-37.

Macartney, N. (2007) Setting the scene for the commemorative workshop. Library and Information Research, 31(97), 1. 